\title{
'It's like a double-edged sword': understanding Confucianism's role in activity participation among first-generation older Chinese migrants in the Netherlands and Belgium
}

\author{
Honghui $\operatorname{Pan}^{1}$ (D) Tineke Fokkema ${ }^{2,3}$ (D) Renfeng Wang ${ }^{1,4} \cdot$ Sarah Dury ${ }^{1,5}$ (D) \\ Liesbeth De Donder ${ }^{1}$ (D)
}

Accepted: 8 August 2021 / Published online: 21 August 2021

(C) The Author(s), under exclusive licence to Springer Science+Business Media, LLC, part of Springer Nature 2021

\begin{abstract}
While activity participation in later life has attracted considerable attention from policymakers and scholars, indoor and outdoor engagement among older Chinese migrants in Europe is understudied. Using in-depth interviews with 21 older Chinese migrants in the Netherlands and seven in Belgium, this study is among the first to explore older Chinese migrants' activity participation experiences from the perspective of Confucianism, the cornerstone of Chinese culture. More specifically, the impact of four acknowledged principles of Confucianism are considered: hierarchical relationships, family system, benevolence and emphasis on education. The findings show that, like a double-edged sword, these four principles have positive and negative effects on older Chinese migrants' activity participation. Hierarchical relationships promote formal organisational participation, yet concurrently dividing the Chinese community into smaller subgroups and endangering solidarity within the community. With regard to family system, which emphasizes intergenerational responsibility and obligation, older Confucianist migrants prioritise taking care of their grandchildren, resulting in less time to participate in outdoor activities. Benevolence, the third principle of Confucianism, restrains older Chinese migrants from political participation while encouraging them to attend community meetings where food is shared. Lastly, emphasis on education, of which self-cultivation is an important aspect, helps older Chinese migrants overcome feelings of loneliness and makes them prefer self-learning activity above formal learning settings (e.g. language learning) organised by the government. The article ends with policy recommendations on how to increase older Chinese migrants' outdoor activities.
\end{abstract}

Keywords Activity · Participation · Confucianism · Older Chinese migrants

Honghui Pan

pan.honghui@vub.be

Extended author information available on the last page of the article 


\section{Introduction}

Activity participation has been on the agenda of policymakers and scholars in the field of ageing since the 1980s. Successful and productive ageing (Morgan, 1986; Rowe \& Kahn, 1987) argues that activity participation is the key to avoid being disengaged from society and find meaning of life as one ages (Tabet, 2016). In the policy domain, the World Health Organization puts forward the principles of active ageing (WHO, 2002) and healthy ageing (WHO, 2015), emphasising the benefits of activity participation and advocating participation as an integral part of active and healthy ageing. Existing literature has identified the role of activity engagement as beneficial to older adults' mental and physical health (Chen \& Janke, 2012; Roh et al., 2015), and participation in activities important to older adults' overall well-being and quality of life (Winstead et al., 2014).

Activity participation includes engagement in formal activities, defined as those that exist in the context of 'codified or prearranged structures' (Barry et al., 2014: 534), and informal ones, initiated by older people themselves (Pan et al., 2019). It ranges from formal activities like attending organised demonstrations and being president or member of a singing club to informal activities such as get-togethers with friends and going to cafés. In this article, activity participation refers not only to those activities happening outside the home but also to those inside one's residence, as previous literature indicates that contribution within families such as taking care of grandchildren inside the home is a central part of family dynamics for older people in later life (Du \& Wang, 2012).

Current policy frameworks and research focus mainly on the benefits of older people's activity participation (Adams et al., 2011) in relatively fixed settings, possibly overlooking those with a migrant background (Torres, 2002). For example, the WHO (2015: 138) stresses that participation in older people's associations can help realise the goal of healthy ageing agendas as these associations can 'organize regular health check-ups, carry out health-education activities and regular physical exercise sessions, as well as conveying knowledge about healthy living and preventing and managing non-communicable diseases'. Whether this also holds true for older migrants with language and cultural barriers (Cela \& Fokkema, 2017; Torres, 2003) remains unaddressed.

The few activity participation studies specifically addressing older migrants in the Netherlands and Belgium restrict themselves mainly to the larger traditional migrant groups such as persons with Turkish and Moroccan backgrounds. From these studies it turns out that activity participation - religious participation in particular (Fleischmann et al., 2016; Smits et al., 2010) - protects Turkish and Moroccan migrants from loneliness (Klok et al., 2017). Moreover, national day participation among older adults of Moroccan, Turkish, Surinamese and Antillean origin living in the Netherlands is determined mostly by their experience with commemoration and celebration in their country of origin (Coopmans et al., 2016). In this article we aim to broaden the activity scope towards Chinese migrants, and towards everyday participation inside and outside the home, including caring for grandchildren, going to dinner with friends and club activities based on membership. 
Sporadic studies about older Chinese migrants' activity participation are examined from perspectives of loneliness and social exclusion and restricted to Englishspeaking countries like Australia and the United States. For example, older Chinese migrants in Australia turn out to have limited social activity engagement because of language barriers and lack of transport means (Ip et al., 2007). A study by Dong et al. (2012) showed that feelings of loneliness are common among the older Chinese population of Chicago, something often identified in terms of lack of participation in social activities. They acknowledge Chinese culture as having an impact on the perception of loneliness, which is different from Western older adults.

To the best of our knowledge, no study has yet focused on older Chinese migrants' activity participation in the Netherlands and Belgium, our topic of interest. Older Chinese migrants have their own distinct culture, which is based on Confucianism (Dong et al., 2012; Laidlaw et al., 2010). The definition of Confucianism is the pragmatic ethics and philosophy of daily life (Millay \& Streeter, 2004; Tang, 1995). Existing research has confirmed its immediate relevance for and influence on a wide range of sociological fields among topics not specific to older people: education (Yu \& Bairner, 2011), communication (Yum, 1988), fertility (Tang, 1995), etc.

Confucianism could well be relevant for activity participation in later life too, as confirmed by previous studies that Confucianism has helped foster an anti-physical activity culture among students (Yu \& Bairner, 2011). Besides, cross-cultural research has confirmed that first-generation older migrants remain invested in elements of traditional Chinese culture (e.g. filial piety; Laidlaw et al., 2010), regardless of the length of time they have been exposed to the culture of the host country (Chuang, 2012). Chinese culture may also prohibit older migrants' activity participation within the host society. For instance, emphasising an indirect communication strategy - being different from mainstream European society, which values direct universal communication mode (Yum, 1988) - might make it difficult for older Chinese migrants to engage in activities with locals. The aim of this study is therefore to explore in which ways Confucianism promotes or poses barriers to activity participation among first-generation older Chinese migrants in the Netherlands and Belgium. In doing so, this empirical research contributes to filling blank spots in migration research on older Chinese people and the influence of Confucianism on their activity participation.

\section{Chinese Migrants and their Confucianist Culture}

\section{Background on Chinese Migration to the Netherlands and Belgium}

Chinese migrants began to arrive in Western Europe at the end of World War I (Skeldon, 1994). These first migrants were comprised mainly of four groups: workers during World War I, single males jumping off the ship for a better life, street peddlers mainly from Wenzhou and Qingtian of the Zhengjiang Province, and students (Li, 2005). Chinese group migrants in Europe are from diverse backgrounds, as some came from former European colonies in Southeastern Asia such as British Hong Kong and Malaysia, the Netherlands East Indies and French Indochina ( $\mathrm{Li}$, 
2005). As the majority of Chinese ethnic migrants came from the former British colony of Hong Kong, many Chinese 'disappeared' into the category of British citizens until July 1997, when Hong Kong's sovereignty was transferred to China (Pang, 1993).

The number of older Chinese migrants has been rapidly increasing in both the Netherlands and Belgium in the last decade. According to Statistics Netherlands (2020), the number of first-generation Chinese (including those from Hong Kong and Macau) in the Netherlands aged 60 and older almost doubled from 4,979 in 2010 to 9,923 in 2019. In Belgium, the number of older Chinese migrants aged 60 and older more than doubled from 1,246 in 2010 to 2,530 in 2019 (Eurostat, 2020). However, compared to 'traditional' migrant groups (Turks, Moroccans, Surinamese), their numbers are still small. Apart from being a minority group, there are other factors at stake accounting for why older Chinese migrants are comparatively invisible: migrants' first-generation strategy of self-reliance and autonomy, geographically dispersed settlement, restraint from voicing needs in public, position in the labour market as small ethnic entrepreneurs rather than labourers (Baker, 1994; Pang, 1993).

\section{History of Confucianism and its Influence}

In $551 \mathrm{BC}$ Confucius was born in the town of Chou, which belongs to the kingdom of Lu during the eastern Zhou dynasty (Yu \& Bairner, 2011). It was a time of instability and conflicts when numerous kingdoms engaged in wars for pre-eminence; this affected Confucius greatly as he fluctuated with the changes of political power. In his work he reflected a wish for social harmony with his experience of personal vicissitudes. Nevertheless, Confucius received no recognition during his lifetime until the Han Dynasty (206 BC-221 AD), when his teachings were embraced and incorporated into China's social and political system to the exclusion of other teachings such as Taoism and Buddhism. Since then, Confucianism has been advocated by most rulers in China's history, including the People's Republic of China under the rule of the Communist party, mostly because it conforms to the economic status of the vast country. Its teachings encourage Chinese people to accept restraints over personal desires and equitable distribution of limited resources among members of a group. The educated elite became regional rulers by passing the exams based on the teachings of Confucianism and afterwards exercised power according to Confucianist prescriptions. By writing legends, drama, folk stories and folk songs for the peasantry, the rulers managed to promote Confucianism as a way of rationalising social order, thus the majority of Chinese society is enmeshed in Confucianism (Fu, 1994).

Existing research has identified Confucianism's influence on various sociological topics: physical activity education, communication, education, corporate management and fertility behaviour research. Chinese under the influence of Confucianism have developed an anti-physical culture that values intellectual achievements rather than athletic competence as manifest in the muscular Christianity of the West (Yu \& Bairner, 2011). On the impact on communication, in contrast to Westerners' universalistic code emphasising fairness and equality (Yum, 1988) the Chinese tend 
to adopt a particularistic communication pattern, regulating relationships based on the status and social position of the other party involved. In the field of education research, Confucianism motivates students to acquire high education while at the same time it has a detrimental effect on students' creativity by stressing mechanical memorisation. Confucianist work ethics also credit hard work at the expense of a healthy lifestyle (Kim \& Sung, 2000), and Chinese workers put more emphasis on personal obligation to others and to groups compared with their Western counterparts (Probst \& Lawler, 2006). In fertility research, Confucianism is found to encourage reproduction and an obvious relationship is discovered between China's large population and Confucianist teachings (Tang, 1995).

\section{Conceptual Framework: Four Principles of Confucianism Regarding Activity Participation}

In this section, the four acknowledged principles of Confucianism - hierarchical relationship, family system, benevolence and emphasis on education (Chen \& Chung, 1994; Hofstede \& Bond, 1988) - will be discussed in order to identify elements that might influence older Chinese migrants' activity participation.

\section{Hierarchical Relationship}

Very different from Western philosophy, which regards individuals as anomic entities, Confucianism sees a person as a relational being who exists in relation to others and is defined within an activity-involved context (Bond, 2008). Confucianism regulates relationships based on Five Codes of Ethics (wulun) - the basic human relationships: between sovereign and subject, father and son, older brother and younger brother, husband and wife, friend and friend (Fan, 2000). There exists hierarchy in these relationships as there is order in nature (Fairbank, 1966). Subjects show loyalty to the ruler; juniors are expected to show seniors respect and obedience; the older brother shows brotherly love and the younger brother shows reverence; a wife shows obedience to her husband; friends are bound by in-group and out-group distinctions (Varenne, 1977). The nature of voluntariness differs between relationships too. For instance, father-son and older-and-younger brother are regarded as absolute relationships beyond individual controlling power, while friendships are, to some extent, subject to people's will (Fan, 2000).

When applying hierarchical relationships to the experience of activity participation, there are three recognised types of influence: particularism, reciprocity and in-group/out-group distinction (Yum, 1988). Firstly, particularism is a key concept for understanding the Chinese's activity participation (Fried, 1969). It is different from the Western universal code of equality regulating relationships based on the same standard: Chinese interact with others according to their status under a particular context, resulting in delicate social interaction patterns with acquaintances and no universal rule for strangers or new people in a new environment. The aim of maintaining a particularistic relationship is to avoid embarrassment and potential 
conflicts (Hwang, 1998). Since activity participation involves interaction among different parties, it intrigues us to what extent older Chinese migrants experience interactions with locals when influenced by Western culture.

Secondly, reciprocity emphasises non-calculation of what one receives or gives in an activity with other members in a group. If one party receives something this time, the party is expected to pay off the gains next time. For example, if Confucianists receive a gift they will show appreciation and return the favour in the near future. Clearly calculating can be regarded as thinking about immediate gains, which is detrimental to establishing long-lasting relationships.

Thirdly, Confucianism distinguishes in-group and out-group members as prescribed by hierarchical and mutually dependent relationships. The nature of mutual dependence requires affiliation to tightly knit groups over a long period of time. Longer-term relationships can last because in-group members can always expect others to give or sacrifice for them, as they believe sooner or later others will reciprocate similarly. The formation of a group can be based on the nature of ties. For example, father-son relationships are expressive ties, friend-friend instrumental ties, and mixed ties arise from common birthplaces or shared experiences such as attending the same school or working together. In individualistic societies, by contrast, allegiance to a group is voluntary and mobility is permitted. People can choose to come together for a common goal and can retain their individuality and independence (Varenne, 1977), joining and dropping out according to their independent will.

\section{Family System}

The family system in Confucianism is characterised by filial piety, which has important implications for understanding intergenerational relationships in Confucianist societies. As filial piety requires that children pay due respect to their parents and take responsibility caring for ageing parents (Chou, 2011; Ng, 2002), it can help consolidate family relationships and enhance familial cohesion (Laidlaw et al., 2010). On the other hand, filial piety can also encourage rigid and authoritarian parenting styles as illustrated in the dual model of filial piety (Yeh \& Bedford, 2003).

The Confucianist family system also emphasises mutual dependence and sacrifice between ageing parents and adult children. Older people influenced by filial piety consider caring for their grandchildren their responsibility as repayment for their children's filiality (Hwang, 1998). There is also gender inequality, as Chinese women are expected to be socially inferior to men: their value as prescribed by hierarchical relationships is reflected as daughters, wives and mothers rather than independent individuals (Yun, 2013).

\section{Benevolence}

Benevolence (jen: 仁) is a collective concept of various Confucianist virtues, of which love is a core concept. According to the theory of benevolence (Hsu, 1971), only through practicing benevolence can humans realise the fundamental three needs: sociability, security and status. This can be realised at different levels. For 
oneself, it means self-discipline and self-cultivation (Hwang \& Chang, 2009) to achieve inner peace and development. Benevolence towards parents is filial piety; towards older people it is respect; towards friends it is faith and trust; towards oneself it is loyalty and responsibility (Chen \& Chung, 1994).

The ultimate aim of practicing benevolence is to attain harmony among people and between people and society (Chuang, 2012; Luo \& Chui, 2016). Benevolence seeks to create warm interpersonal feelings and avoid any conflicts between people and society. A harmonious status of benevolence can be reached at the expense of personal interests and individual gains (Chuang, 2012; Lu et al., 2003). It also impacts how Confucianists consume food: for example, the Chinese think about food as something to share in a group (Ma, 2015) and attach importance to group harmony in their food preferences (Chang et al., 2010), which is in sharp contrast with Western individual food choices for everyone.

\section{Emphasis on Education}

Confucianism believes on the perfectibility and educability of human beings. The Chinese educational system focuses on passing exams, which originates from its 1300-year-old tradition of keju, a system used to recruit state officials (Fu, 1994). In ancient times the Keju system gave all people in society an equal chance to become a ruler without official connections (Yu \& Bairner, 2011).

Positive influence in terms of learning participation includes Confucianists' motivation to acquire higher education and degrees; this accounts for the success of economic activities in East Asian countries influenced by Confucianism, including Hong Kong, Taiwan, Singapore and South Korea (Chen \& Chung, 1994). Confucianist teachings also encourage self-cultivation (xiuyang) and emphasise individual responsibility in educating and perfecting oneself as well as respect for the authority of the teacher (Chuang, 2012). The negative influence is that Confucianism focuses on learning participation in a mechanical way. Repetition and memorisation are valued without provoking thought or meaning (Kim, 2007), and are considered detrimental to nurturing creativity and originality (Chan, 1999).

\section{Data and methods}

To answer the research inquiry of cultural influence and older Chinese migrants' participation, we adopted the research method of one-on-one in-depth interviews. In-depth interviews enable researchers to gain insightful answers into abstract topics like attitude and perceptions, and pose follow-up questions or probe for more information (Ryan et al., 2009). The recruitment strategy involved convenience and snowballing sampling. Invitation letters to participate in the study were sent to ten activity centres for older adults in the Netherlands and Belgium. The first and third authors, who conducted the in-depth interviews, have a social network in both countries for reaching out to older Chinese migrants. The geographically proximate locations of the Netherlands and Belgium also made it feasible for the authors to engage 
in frequent travels to interview participants. Chinese older migrants likewise have networks and organisations that operate throughout the Netherlands and Belgium, neighbouring countries that share a common history and language.

The letter briefly described the aim and content of the research. In order to avoid a selection bias that older adults who go to activity centres are active, and to make sure that less active older Chinese were not left out of the study, we also sent the invitation letter to three social workers whose clients are mostly of Chinese background. In this way a diverse range of older Chinese migrants was reached and informed about the opportunity to participate in the study. In the end, 21 older Chinese migrants in the Netherlands and seven in Belgium gave consent to participate after being informed about the content of the interview, confidentiality of their identity, and their rights to withdraw if they felt uncomfortable during the process.

There were 11 male and 17 female participants in the study (see Table 1). The participants comprised 19 visitors to three local activity centres for older adults in the Netherlands, three of whom were activity organisers themselves (N1F1; N1F6; N1F12). Two older persons in the Netherlands were interviewed at home because of their poor health condition (N1M7; N1F7). The seven interviews in Belgium were all conducted at older adults' homes. The average age of participants was 69 , and they had lived in the Netherlands or Belgium for an average of 35 years. Average monthly income was 908 euros. The majority had completed at least secondary school (generally until the age of 16 in China). About $43 \%$ of interviewees $(\mathrm{N}=12)$ migrated as labourers and an equal number $(\mathrm{N}=12)$ relocated because of family reunification. The remaining four were the so-called zero generation (King et al., 2014), who mostly came to look after the grandchildren of their first-generation adult children. In terms of living arrangements, nine people lived alone and 18 with their spouse. One lived with spouse and adult son's family (daughter-in-law and one grandson).

The interview process involved four parts. After the researcher introduced the aim and process of the interview, interviewees were asked about their activity engagement. Questions were framed so they were easy to answer. For example, how do they spend a typical week and who are the participants and organisers of activities they participate in. If an activity is formally organized, it is coded a formal activity otherwise an informal one. Next, they were asked about the impact of relocation to Europe on their activity engagement. Lastly, they were asked to share their understanding of Confucianism and encouraged to share a story of their activity engagement seen from their perspective on the influence of Confucianism. Each interview lasted about 30-45 min and was recorded, then transcribed verbatim by the first and third authors, who are native Chinese speakers.

Participants' names were replaced in the analytical process. The research method of thematic content analysis was adopted, using qualitative analysis software MAXQDA (VERBI Software, 2017) to code the interviews. The abovementioned four principles of Confucianism - hierarchical relationship, family system, benevolence and emphasis on education - were adopted as main codes. The first and third authors read through all transcribed texts to extract the texts of participants' activities and influence of Chinese culture on their activity engagement. Drawing from extracted texts, both authors developed sub-codes and pointer words for each of the four 


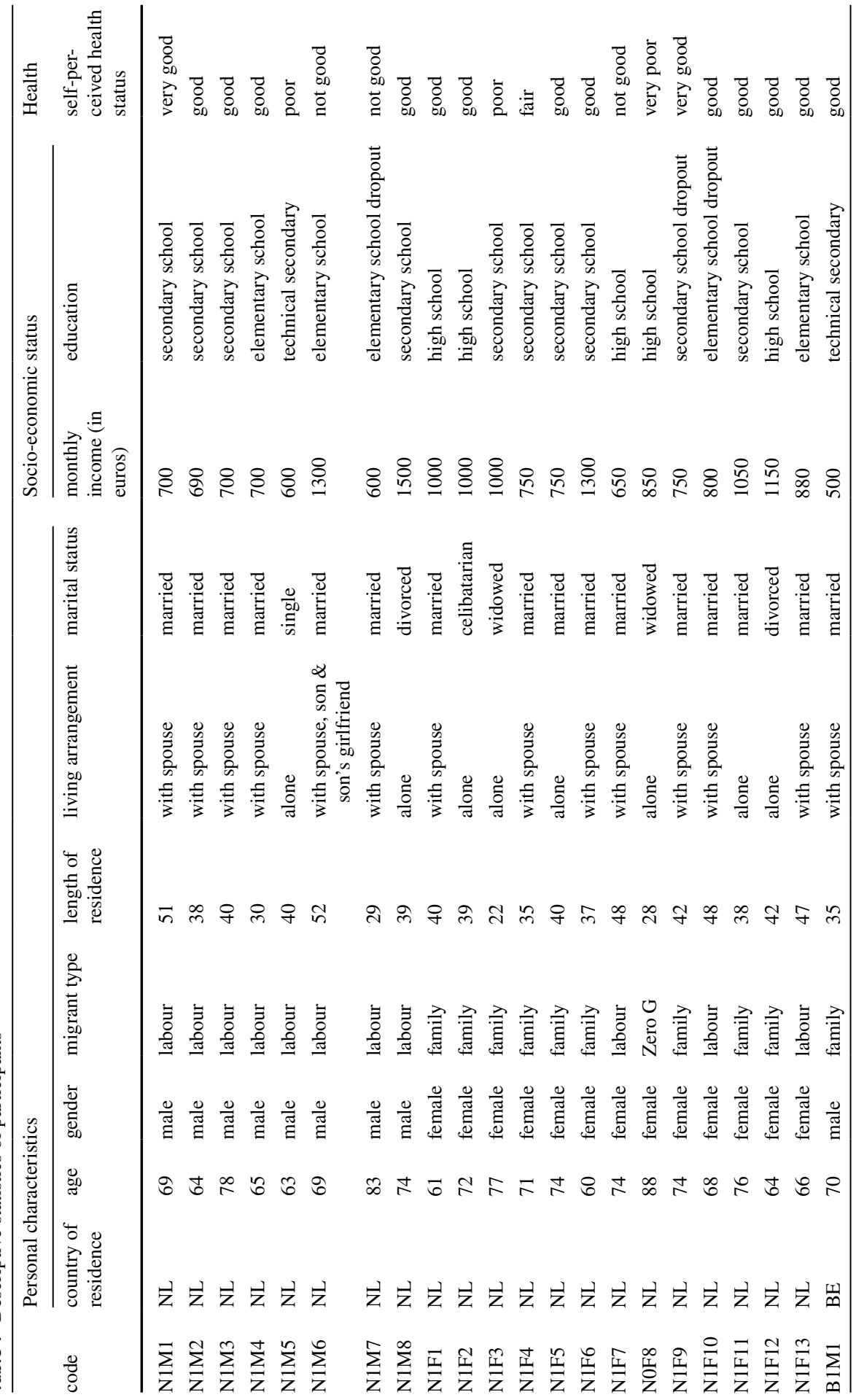




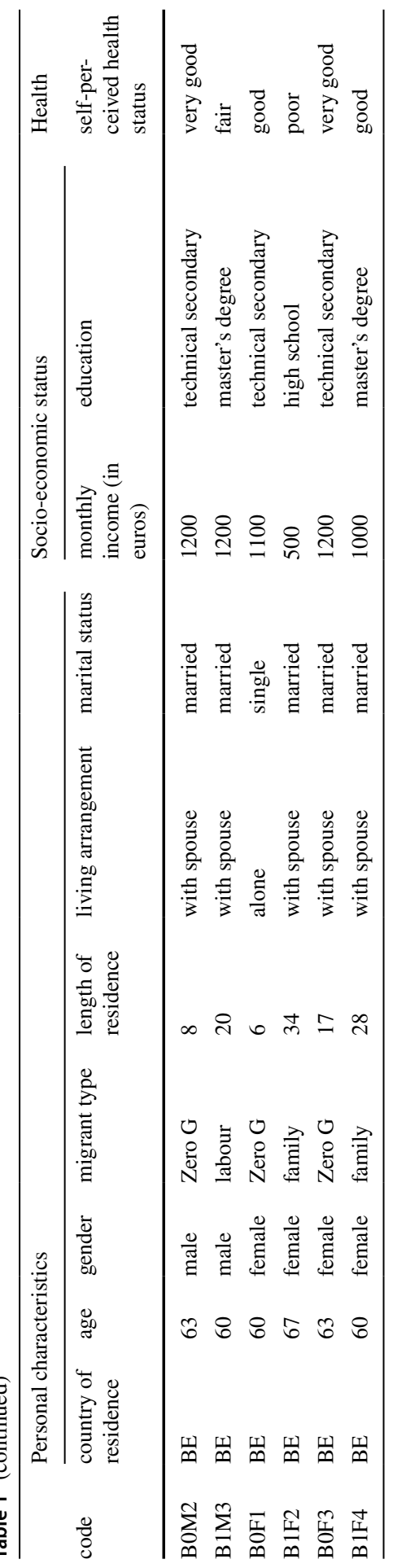


principles of Confucianism (see Table 2). For example, for the code of benevolence, pointer words such as peace (太平), empathy (同情), goodwill (善意) or anonymous conflict (冲突) and collision (摩擦) were marked. Following the criteria, the first and third authors then coded separately and extracted the paragraph or stories containing the pointer words. Inter-rater reliability was ensured as the two researchers first labelled the same manuscript. Afterwards, they compared codes to see if there were any differences and findings were discussed until consensus was reached. For instance, an account of how an older Chinese migrant woman in the Netherlands regretted the loss of an opportunity to attend Dutch courses due to the pressure from her husband who took it for granted that a woman should sacrifice for her husband, children and the family. One researcher labelled it "hierarchical relationship" as the pointer word husband-wife was one of Wulun relations. The other labelled it "family system" as the pointer word family was also present. After discussion, the two authors agreed on the code of "family system" as the story also touched upon other family members like children.

\section{Results}

The findings show that first-generation Chinese older migrants engage in a wide range of both formal and informal activities. Formal activities include being a member of traditional Chinese clothes clubs, singing clubs and organisations for older Chinese adults; attending organised activities (e.g. language courses, health-related lectures, movie nights and sport events) at local community centres; and political participation. Informal ones include social activities with neighbours or friends (e.g. going out to eat), visiting adult children, taking care of grandchildren and pursuing personal hobbies (e.g. calligraphy practice, Tai-Chi, Qi-Going exercise).

It should be noted that Confucianism was found to be relevant for older Chinese migrants' activity participation, except for two participants. The transcribed texts of one male participant aged 70 in Belgium (B1M1) and one 76-year-old in the Netherlands (N1F11) did not show any influence of Confucianism's four principles on their activity participation. The other 26 participants reported at least one of the four principles' influence on their activity engagement in the host society. The experience of the impact of the four principles of Confucianism on older Chinese migrants' activity engagement is presented in detail as follows.

\section{Experience of Hierarchical Relationships in Activity Participation}

Three elements of hierarchical relationships are found in the interviews to have an impact on older Chinese adults' activity participation: particularism, reciprocity and in-group/out-group distinction. In contrast to the Western code of equality, particularism regulates how the Chinese interact with people based on the extent of intimacy with and the status of the other party involved; this serves as a barrier for older Chinese to make friends in a social setting in the host country. A 60-year-old woman $(\mathrm{B} 0 \mathrm{~F} 1)$ told the interviewer that she could not understand in a Western party 


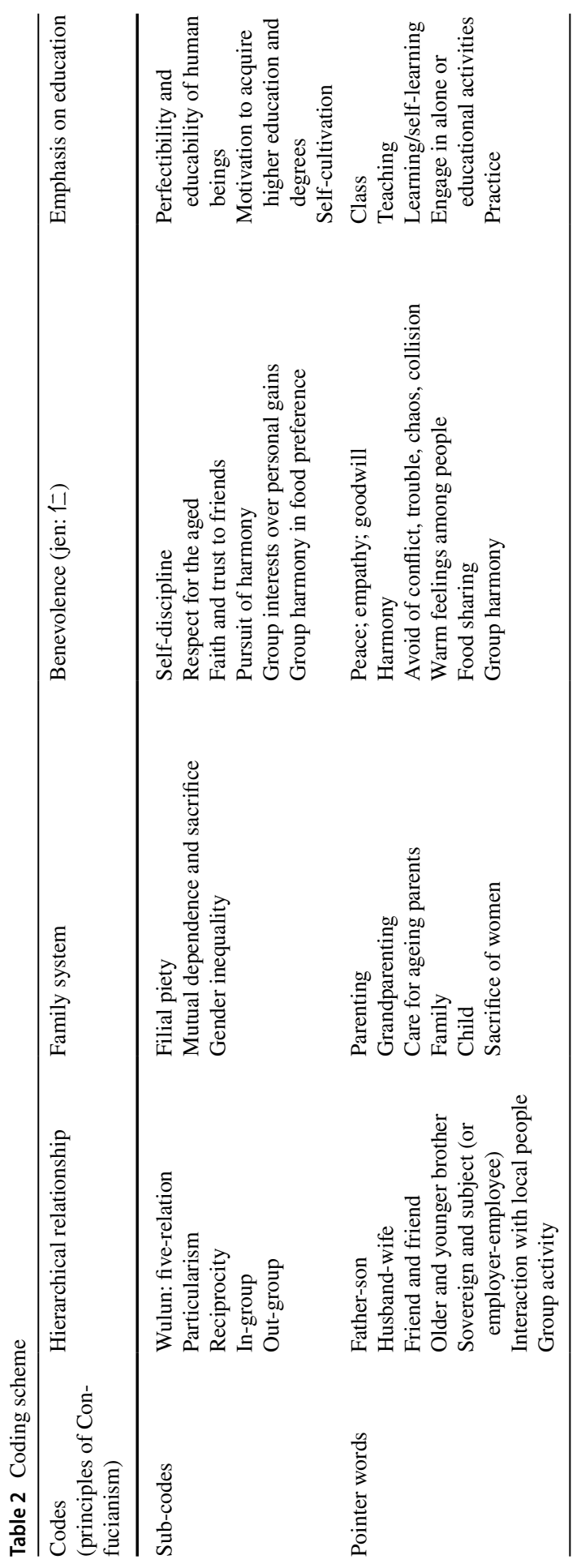


that 'people just talked freely with any stranger like they have known each other for a long time'. An older man (N1M7) described that he wanted to make friends with his boss but did not know how to initiate a conversation: 'It seems very easy for my Dutch colleagues who can happily joke with their boss. I might look very serious to my boss as I want to show due respect to my boss. You know, he is the boss and a little bit of obedience and respect, in my opinion, is necessary'.

In hierarchical relationships, reciprocity means no calculation of personal gains or losses in a sincere friendship. This stands as a barrier to activity participation in mainstream society, particularly with native friends. One female interviewee (B0F3) expressed her shock when she was invited to a birthday dinner and had to split the bill (or go Dutch as described by the interviewee herself). She felt that it hurt her feelings when she was asked to pay.

I couldn't understand the existence of going Dutch at every meal, even when the guests are family members. The father, mother, brothers, sisters, they are the dearest ones in your life but they have to calculate an exact number everyone should pay. I don't think it's a big deal: this time you pay, next time I pay. The difference of the price won't be a big deal. This is how it goes in our culture. Once I got invited to a birthday dinner at a restaurant and everyone invited had to pay. Oh, I can't imagine being invited and having to pay. Don't you think it hurts feelings to ask guests to pay?

According to four interviewees (N1M3; N1F1; N1F6; N1F12), three of whom were also activity organisers in the Netherlands (N1F1; N1F; N1F12), in-group/ out-group distinctions based on where people come from limits older Chinese's participation opportunities to their own small circle. One of them expressed her regrets when she experienced the separation within the Chinese community.

To be honest, we, the Chinese, are very conservative and tend to stay inside our own houses and are reluctant to go out. Other migrant groups have had this kind of event a long time ago, however we only started this year. I also need to do a lot of work to promote it. One thing very difficult for me is that older Chinese people seem to stick together but they have their own small groups. They are good at this: 'You come from Hong Kong, I come from the mainland, and she comes from Canton (a southern province in China). Oh, he comes from Taiwan'. In the end, it turns out [like this]: 'I don't go to your gatherings and you don't come to mine'. (N1F6)

While in-group/out-group distinctions are possibly detrimental to larger Chinese community participation, in-group members felt an obligation to join group activities, showing commitment to group affiliation and loyalty possibly from the influence of collectivist thinking.

I belong to the group of Qipao (traditional Chinese women's clothes). I once thought I was old and not beautiful. It was like a joke for others if I stood on the stage and gave a performance in Qipao. I once wanted to stop going to the exercise activities of the Qipao club. Then the president of Qipao came to me and she said to me: 'We are a group and we are here to demonstrate the beauty 
of Chinese culture'. Sometimes when the group needed to go to some places to give a performance like for the older people at the nursing home, they asked me to attend because some members couldn't go because of work or study. If I got requests like this one, I would always go. I feel I have the obligation to do it. It is for the honour of the group. (B0F1)

\section{Experience of the Family System's Influence on Activity Participation}

The family system in Confucianism has been found to impact older Chinese migrants' participation, which emphasises the mutual dependence between ageing parents and their adult children. Interviewees (N1F4, N1F5, B0F1) reported depending on and sacrificing for their adult children, and consider taking care of grandchildren as one of their responsibilities. In the meantime, they expect their adult children to take care of them when they are frail and need care, as prescribed in the concept of filial piety. According to N1F2 and N1F4, the difference of Chinese and local people in treating their family members prevented her from developing a profound relationship with them. N1F2 commented 'Chinse parents would buy houses for their son or daughter, devote to grand-parenting. Dutch people are not that generous; my money is mine and your money is yours. They sacrifice little for their children'.

Five of our participants (N1F3, N1M1, N1M6, B1M3, B0M2) mentioned that the main reason for their staying in Europe was because their children are here. They also prioritised taking care of grandchildren over going to social activities. A male migrant who had lived in the Netherlands for 52 years said he had participated in almost no activities and experienced feelings of loneliness due to a lack of activities he could participate in. He also missed China, where he had relatives and friends. In the end, he added that he could not go back because his child is here in Europe.

I don't do many things here (in the Netherlands). Just my only child and barely any friends. If I spent my retirement life in China, I think I would be less lonely with my cousins around. I could visit one relative this weekend and the other one another weekend. Here everything is different and I have my only child here. Where the child stays decides where I can stay. If my child had a career in China, of course I would go back. If he is here, I cannot go back. (N1M6)

An older woman living in Belgium talked about going to see movies at the Chinese cultural centre in Brussels, explaining she often could not go because of her responsibility of caring for her grandchild.

Interviewee: the main reason for me staying here is my children. If they were in China, I would go back. It's simple. Family must come first and after come friends. My life here centres on the life of my children. I help take care of my grandchildren. (B0F3)

Researcher: What other activities do you do besides taking care of your grandchildren?

Interviewee: I also go to see movies at the Chinese cultural centre at the Confucius institute here. It's free and starts at half-past six. Most of the time I can't 
go because I have to pick up my grandchild from school. My daughter-in-law works at a hospital and her shift sometimes starts in the early morning or late morning. If she goes to work for a late shift, she cannot go and pick up her son. We need to help out twice or three times a week. We are on call, you know. Anytime they need us, we will go. (B0F3)

Filial piety also requires absolute respect for the ageing parents in a traditional Chinese family and mutual sacrifice between family members. A 65-year-old male participant in the Netherlands described his confusion when talking about intergenerational relationships in Europe and could not understand the existence of a legal adult age for his children when he could not interfere in his children's life anymore.

Here in Belgium, after a child comes of age, he is independent and the parents cannot discipline [the child] or try to interfere in the child's life anymore. But in China, we don't do it this way. If you once were a family member, you will always be a member. You will continue to be my child, the kid, even after you are sixty years old. In some countries, sixteen is the cut-off age while in others eighteen. For me, this doesn't make any sense since every child is unique and undergoes a different maturity process in terms of mental growth. Our culture is good in this respect. We live in a group and we always take care of each other and we sacrifice for each other. (N1M4)

A clash was found between older Chinese adults influenced by filial piety and their children who have been educated and immersed in individualistic European culture. This poses a barrier for older Chinese adults to participate harmoniously within the family context. The following is what a 60-year-old man complained about - her daughter acting like a stranger to him instead of being filial.

If you have your own house in China, you parents want to pay you a visit. They can go to your house at any time, right? It's not the case here. My children would require me to call them first to make an appointment. What's wrong with them? I am their father and I have to make appointments to see them?! This is something you do to strangers, not to your father. Both my son and daughter treat me like this. I don't visit them often because of their behaviour. I am very sad about this and would be ashamed to mention it to my relatives in China. (B1M3)

Our findings also show that older Chinese women migrants experienced loss of participation opportunities because of the hierarchical and unequal relationship between wife and husband in the family. Wulun in Confucianism regulates that the status of a woman is subordinate to her father before marriage, then to her husband after marriage, later to her son. In other words, a woman's value is realised in being a daughter, a wife and a mother, even a grandmother. An older woman (N1F6) who used to work in the restaurant business in a small Dutch city was very proud of herself when talking about teaching herself and passing the Dutch language exam in order to get the certificate for the restaurant business. She showed regrets for not being able to continue learning Dutch because of the expected responsibility towards her husband and children. 


\section{Experience of the Influence of Benevolence on Activity Participation}

The goal of benevolence, the ultimate harmony between people and society, is found to have a negative impact on older Chinese migrants' informal participation with locals (e.g. day-to-day conversation) as well as formal participation (e.g. political involvement in mainstream society). A 78-year-old participant in the Netherlands told the interviewer that being sick and diagnosis of cancer among his peers was considered a 'shame' and 'not something to share with friends' (N1M3). A 64-yearold woman, president of an association for older adults in a medium-sized Dutch city, explained why she refrains from sharing bad news in her daily communication with other people:

Europeans are very open and they say everything directly what's on their minds. However, for the Chinese there is an old saying: 'For the harmony of the public, do not disclose family shame to others'. Therefore, we tend to share good news and refrain from sharing bad news. (N1F12)

Concerning formal participation, a few interviewees described participating in chaotic political demonstrations where participants cause trouble with the police and disrupt the social order. Out of fear of upsetting the harmony with society, they tended to refrain from letting their voices be heard in the larger society by participating in political activities. A woman aged 67 who has lived in Brussels for 34 years stated why she does not feel like participating in political activities:

Belgian people are nice to us and there is nothing wrong with the people and the country. We take care of ourselves and I've been afraid that my presence will cause any trouble to the country. That is why I have never participated in any of the demonstration activities or political activities. It is meaningless you know, it causes chaos and nothing more. (B1F2)

Benevolence is also characterised by warm feelings between members of society, which is identified as a barrier to informal participation with the local Dutch and Belgians. A 83-year-old man in the Netherlands lamented to the interviewer that he did not have many local or Chinese friends in the first years after his arrival, and he found a lack of intimacy and closeness even between his best friends.

We didn't have any friends in the early years after my arrival. My wife and I, we are not used to how friends treat each other. We once visited a Dutch friend's house and the atmosphere was so... I don't know how to put it... maybe awkward? We had known each other for some time back then, but I felt like that we were still strangers. In China, I go to a friend's house and I knock at the door, my friend will ask: 'Who is this?' I will answer: 'Me'. I don't even have to answer my name. My friend can tell from my voice. This is the society I'm familiar with. I could go to visit a good friend's house in the evening and have dinner together. I don't have to tell them in advance. My friend will always welcome me. Not here. You have to make appointments even with your best friend. (N1M7) 
Another interesting finding is that seven interviewees (N1M8, N1F6, N1F8, N1F9, N1F12, N0F13, B1M3) mentioned the importance of food and food-sharing in terms of their participation. N1F6 commented 'Food sharing is a very important aspect of our culture and we older people found it very interesting to share with people at a round table'. The activity venue was offered for free by the local government but regulations prohibited attendants from bringing their own food - which, according to N1F6, was the reason that some older persons stopped participation in the activities organised at the activity centre for older adults. N1F12 was very proud of herself in preparing tiantang (a kind of sweet Cantonese soup) and said more people would come if they were told there was tiantang ready for them to taste. B1F4, the founder of a singing club in Belgium, described the presence of food when the club first got started was one important factor to attract potential participants.

At the same time, prioritising food enjoyment can serve as a barrier to participation. B1M3, a member of the Chinese chorus in Belgium, told that people came to join the group 'mostly for the sake of eating and having fun' instead of practicing singing skills, and complained about the unprofessionalism of the singing group. B0M2 told the interviewer he had no time left for activity participation because he needed to work and only had one day off work each week. On the free weekend day, he prioritised going to the bull market in Molenbeek to shop for cheap food. Afterwards, shopping and preparing the food would take a whole day. The prioritisation of food was also explained by a man aged 74 who had lived in the Netherlands for 39 years:

You know Chinese people enjoy eating and enjoy cooking. Every Monday there is a food market in the city from 8 am to about $2 \mathrm{pm}$. I can buy fresh fish, vegetables, kitchenware, clothing and other living necessities there. It is different from supermarkets like Aldi. Food in the Monday market is very fresh. So I hope the elderly centre can change its activity time to another time. Now the activity day is Monday. So I cannot go to the activity. (N1M8)

\section{Experience of the Influence of Emphasis on Education on Activity Participation}

Self-cultivation, a pursuit of harmony within oneself, emphasises the individual's responsibility in self-education and personal well-being. The study found that when participating in learning activities, older Chinese migrants expressed a tendency to refrain from organised group learning out of fear of being trouble to the teacher. The consequence might be that they lose an opportunity to properly learn the language of the host country in a group setting (N1M5; N1M7; N0F8; N1F9).

I don't like going to organised classes here. As an immigrant, I was required by the government to learn Dutch in my community. But I'm very uncomfortable in a group. The teacher often asks me questions. I am scared by the prospect that if I cannot answer them, I would cause more trouble to the teacher. They were being very nice and kept asking me if I could understand. Maybe others don't think that way but I feel like that I would be a bother to the teacher if I wasn't able to answer the question. (N1F9) 
Self-cultivation and discipline were also found to be positively related to older Chinese migrants' informal participation during their own spare time. This means that an older adult - though not embedded in mainstream society or within the Chinese community - does not automatically feel lonely, which in a sense brings about inner peace. N1F10 talked enthusiastically about her teaching herself Tai-chi and stressed several times that mastery of Tai-chi benefits her physical well-being. N1F3 mentioned practicing Chinese calligraphy by herself and commented on feeling happy after completing a piece of work.

N1F12 said she went through a hard time after divorcing her Dutch husband with two young boys but she recovered and came to herself after singing Karaoke on her own for two hours. After singing, she said: 'I seemingly forgot the unhappy things afterwards and recovered the strength to carry on'. A 63-year-old woman in Belgium commented on how she coped with the quietness of Europe when she first came here:

I used to enjoy singing and dancing very much. I found it very quiet after I came here (Belgium), so I went to the media store and bought a loudspeaker to play music at home. I have karaoke at my house and a microphone. In this way, I don't feel lonely anymore at my house. I think people should be responsible for their own well-being. I can continue the hobbies I had in China even if I'm alone. (BOF3)

\section{Discussion and Conclusion}

This study has shown the dual effect of the role of Confucianism in Chinese culture on older Chinese migrants' participation experience in the Netherlands and Belgium. The four principles of Confucianism have both negative and positive effects on older Chinese adults' activity participation. In a sense, this overall finding is in line with cross-cultural acculturation theories among migrants suggesting that culture, posing possible barriers to migrants' activity participation in the host country, can also be a source of strategies to cope with unwanted circumstances (Aldwin, 2007; Castro \& Murray, 2010). It also corroborates previous migrant studies that point out that older migrants can draw from their own ethnic community or culture to integrate and socially participate in mainstream society (Berry, 1997).

Looking at the four principles of Confucianism in detail, the first finding on the cultural elements of hierarchical relationship - particularism, reciprocity and ingroup/out-group distinction - appears to be that they are detrimental to older Chinese migrants' participation with locals, mainly because of different social etiquettes and norms (e.g. interaction based on equality versus status, 'going Dutch' versus the principle of no-calculation in long-term friendships). In-group belonging, on the other hand, serves as facilitator for older adults to participate in formally organised activities for their own subgroup. For example, older Chinese migrants emphasised group honour when making a decision about whether or not to participate in an activity. This confirms prior research maintaining that the Chinese attach great importance to expected reactions of others in deciding upon their behaviour (Yang, 
1981). And yet, in-group/out-group distinctions are detrimental to participating with other Chinese subgroups. In this sense, the present study contributes to the current debate about Confucianism' element of hierarchical relationships by showing that, in the context of European society, in-group/out-group distinctions divide Chinese migrants into smaller subgroups and harms collectivistic solidarity in activities within the Chinese community.

The second finding about the influence of the family system confirms previous research outcomes that the Chinese emphasise personal responsibility to others (Chuang, 2012), particularly mutual interdependence among family members. Our study shows that older Chinese migrants are actually very active in the family domain, especially older women. The finding of gender differences regarding intergenerational relationship and giving and receiving help can be found in migrants with origins from collectivist or traditional countries or societies. For example, older Greek Cypriots migrants in London also gave a similar culturally determined discourse about their family (Cylwik, 2002). This however sometimes serves as a barrier to participate in social outdoor activities because of ageing migrants' lack of time. As required by the mutual dependence of the Confucianist familial system, ageing parents consider it their duty to educate and take care of their children and grandchildren. Filial adult children are willing and expected to repay and take care of their ageing parents both emotionally and financially. This study also contributes to prior research by adding that possible conflict between ageing Confucianist parents and their adult children is influenced by individualistic European culture. This possible difference in cultural beliefs serves as a barrier to familial participation of ageing Chinese migrants.

The third finding regarding the role of benevolence reveals why older Chinese migrants refrain from participating in formally organised political activities and partly explains Chinese migrants' silencing and invisibility in the host society. It confirms previous studies stating that the Chinese's collectivist concern urges them to avoid conflict, maintain social order (Lu et al., 2003) and subordinate personal interest to that of the group or the nation as a whole. It also serves as a barrier to informal participation among local friends, as benevolence emphasises warm interpersonal feelings for the sake of which it is necessary to blur interpersonal boundaries. Individualistic European societies do have a marked line in interaction among friends, and this difference might account for why older Chinese migrants find it difficult to engage in daily activities with local friends. The finding of older Chinese migrants' prioritising food enjoyment is consistent with Confucianist teachings about food. As a Confucianism masterpiece states - 'hunger breeds discontentment' - pursuing cuisine is regarded as an important aspect of satisfying one's needs, an important aspect of the theory of benevolence (Hsu, 1971). This theory helps explain why older Confucianists prioritise food enjoyment over participation and why the addition of Chinese food to the activity venue is an extra attraction. Older Chinese migrants' preference for Chinese cuisine confirms previous research results that food habits are long-lasting and resistant to change once established (Fieldhouse, 1986).

The last finding shows that the influence of emphasis on education, the fourth element of Confucianism, on older Chinese migrants' participation is also doublefaceted. Self-cultivation and self-development helps ageing Chinese migrants to be 
'active alone'. The interviewees often mentioned engaging in activities without the involvement of others, such as Chinese calligraphy, Tai-chi and singing. They find that these solitary activities enable them to cope with feelings of loneliness or stressful events after migration. In terms of learning participation, it was found that older Chinese migrants show a tendency to refrain from organised group learning activities, which confirms previous research on Confucianist adult learners' preferences in the United States (Chuang, 2012). The interviewees in this study expressed a tendency to withdraw from free European class environments where they learn to ask the teacher questions freely and the teacher elicits frequent feedback from students. This in a sense corroborates previous studies confirming Confucianist Chinese's stronger desire to avoid uncertainty in learning situations (Hofstede et al., 2010). They will avoid possible conflicts with instructors, who are wise role models and cannot be challenged by students (Barron \& Arcodia, 2002).

As suggestions for future studies on Confucianism and older Chinese migrants, the possible correlations and bridging cultural elements between the four principles of Confucianism can be explored. For example, the concept of mianzi (worrying about losing face) is related with reciprocity, harmony and emphasis on education (Haidong \& Walker, 2011; Yunong \& Wu, 2012). It would also be interesting to study the topic from life-course and comparative perspectives, such as the differences and similarities in cultural beliefs and their impact on activity participation choices between older people in China and in Europe. For instance, how does culture's impact on migrants' participation change over one's life-course? How is the cultural impact of Confucianism different from other cultures such as Moroccan or Turkish cultures in terms of activity participation? These questions require further comparative research.

This study has some limitations. Two critical considerations can be formulated. First, the relatively small sample size of 28 older Chinese migrants based on convenience sampling is not inclusive and cannot represent the heterogeneous group of Chinese migrants. Although this was never the intention in our qualitative study, we have to recognise that the reliance on key informants, mostly social workers in activity centres for older people, might result in possible selection bias as the majority of frail older migrants are left out of this study. Second, the qualitative research method used in this study might not be the most appropriate to understand the topic in depth, as the subject of culture is complex. For example, older participants with a lower educational level took quite some time to think of a story relating to Chinese culture. A vignette study (Finch, 1987; Turper, 2017) providing a hypothetical situation to the interviewees has proven more suitable in exploring participants' perceptions, values and attitudes towards an abstract topic like culture and might be a possible recommendation for future research.

Despite these limitations, this study is the first to provide empirical data on the role of Confucianism in older Chinese migrants' activity participation, and our findings offer insight for policymakers as to how to attract more, and more frequently, older Chinese migrants into their sponsored activity programmes as well as increase informal contacts. As for policy recommendations, the experience of older Chinese migrants' culture in activity participation should be taken into consideration. Firstly, more activities for the subgroups (e.g. mainland Chinese) can be developed 
as loyalty and more familiarity with other members in this subgroup can motivate them to join. Secondly, the timing of activities devised for older Chinese migrants should consider their priority for grand-parenting and avoid the 'peak hours' with the family. Thirdly, food enjoyment is valued highly among older Chinese migrants, so more activities that include food-sharing should be arranged. As shown in the study, a few interviewees complained about the government prohibiting them from bringing their own food to share with other participants. Lastly, relevant government agencies offering language inclusion courses should also consider the learning preference of avoiding uncertainty in class, and more structured learning segments where older Chinese migrants can anticipate the instructor's questions should also be added to learning activities.

Acknowledgements We would like to thank all the interviewees who participated in the research.

Funding This study was funded by China Scholarship Council (grant number 201506360099).

Declarations

Conflict of interest The authors declare that they have no conflict of interest.

\section{References}

Adams, K. B., Leibbrandt, S., \& Moon, H. (2011). A critical review of the literature on social and leisure activity and wellbeing in later life. Ageing and Society, 31(4), 683-712.

Aldwin, C. M. (2007). Stress, Coping, and Development: An Integrative Perspective (2nd ed.). Guildford Press.

Baker, H. D. R. (1994). Branches all over: The Hong Kong Chinese in the United Kingdom. In R. Skeldon (Ed.), Reluctant Exiles? (pp. 300-301). Migration from Hong Kong and the New Overseas Chinese. M.E.Sharpe.

Barron, P., \& Arcodia, C. (2002). Linking learning style preferences and ethnicity: International students studying hospitality and tourism management in Australia. Journal of Hospitality, Leisure, Sport \& Tourism Education, 1(2), 15-27.

Barry, M., Wilkinson, A. Gollan, P. J. \& Kalfa, S. (2014). Where are the voices? New directions in voice and engagement across the globe. In Wilkinson, A., Wood, G. \& Deeg, R. (Eds), Oxford Handbook of Employment Relations: Comparative Employment Systems (pp. 522-540). Oxford, New York.

Berry, J. W. (1997). Immigration, acculturation, and adaptation. Applied Psychology: An International Review, 46, 5-43.

Bond, M. H. (2008). The Psychology of the Chinese People. The Chinese University of Hong Kong.

Castro, F. G., \& Murray, K. E. (2010). Cultural adaptation and resilience: Controversies, issues, and emerging models. In J. W. Reich, A. J. Zautra, \& J. S. Hall (Eds.), Handbook of Adult Resilience (pp. 375-403). The Guildford Press.

Cela, E., \& Fokkema, T. (2017). Being lonely later in life: A qualitative study among Albanians and Moroccans in Italy. Ageing and Society, 37(6), 1197-1226.

Chan, S. (1999). The Chinese learner - A question of style. Education + Training, 41(6/7), $294-305$. https://doi.org/10.1108/00400919910285345

Chang, R. C. Y., Kivela, J., \& Mak, A. H. N. (2010). Food preferences of Chinese tourists. Annals of Tourism Research, 37(4), 989-1011.

Chen, G.-M., \& Chung, J. (1994). The impact of Confucianism on organizational communication. Communication Quarterly, 42(2), 93-105.

Chen, T.-Y., \& Janke, M. C. (2012). Gardening as a potential activity to reduce falls in older adults. Journal of Aging and Physical Activity, 20(1), 15-31. 
Chou, R. J. A. (2011). Filial piety by contract? The emergence, implementation, and implications of the "family support agreement" in China. The Gerontologist, 51(1), 3-16.

Chuang, S.-F. (2012). The relationship between cultural values and learning preference: The impact of acculturation experiences upon East Asians. International Journal of Training and Development, $16(1), 1-22$.

Coopmans, M., Jaspers, E., \& Lubbers, M. (2016). National day participation among immigrants in the Netherlands: The role of familiarity with commemorating and celebrating. Journal of Ethnic and Migration Studies, 42(12), 1925-1940.

Cylwik, G. (2002). Expectations of inter-generational reciprocity among older Greek Cypriot migrants in London. Ageing and Society, 22(5), 599-613.

Dong, X.-Q., Chang, E.-S., Wong, E., \& Simon, M. (2012). Perception and negative effect of loneliness in a Chicago Chinese population of older adults. Archives of Gerontology and Geriatrics, 54(1), 151-159.

Du, P., \& Wang, F. (2012). Productive ageing in China: Development of concepts and policy practice. Ageing International, 38(1), 4-14.

Eurostat. (2020). Population on 1 January by age group, sex and birth of country. Accessed 5 November, 2020 from https://ec.europa.eu/eurostat/databrowser/view/migr_pop3ctb/default/table? lang=en

Fairbank, J. K. (1966). How to deal with the Chinese revolution. The New York Review of Books, 6, 12.

Fan, Y. (2000). A classification of Chinese culture. Cross Cultural Management: An International Journal, 7(2), 3-10.

Fieldhouse, P. (1986). Food and Nutrition: Customs and Culture. Croom Helm.

Finch, J. (1987). Research note: The vignette technique in survey research. Sociology, 21(1), 105-114.

Fleischmann, F., Martinovic, B., \& Böhm, M. (2016). Mobilising mosques? The role of service attendance for political participation of Turkish and Moroccan minorities in the Netherlands. Ethnic and Racial Studies, 39(5), 746-763.

Fried, M. H. (1969). The Fabric of Chinese Society: A Study of the Social Life of a Chinese County Seat. Octagon Books.

Fu, X. (1994). Tangdai keju yu wenxue (Civil service examination and literature in Tang dynasty), Wenshi chuban she, Taipei.

Haidong, L., \& Walker, G. J. (2011). Does "face" constrain Mainland Chinese people from starting new leisure activities? Leisure/loisir, 35(2), 211-225.

Hofstede, G., \& Bond, M. H. (1988). The Confucius connection: From cultural roots to economic growth. Organizational Dynamics, 16(4), 5-21.

Hofstede, G., Hofstede, G. J., \& Minkov, M. (2010). Cultures and Organizations: Software of the Mind; Intercultural Cooperation and its Importance for Survival (3rd ed.). McGraw-Hill.

Hsu, F. L. K. (1971). Psychosocial Homeostasis and Jen: Conceptual tools for advancing psychological anthropology. American Anthropologist, New Series, 73(1), 23-44.

Hwang, K.-K. (1998). Filial piety and loyalty: Two types of social identification in Confucianism. Asian Journal of Social Psychology, 2(1), 163-183.

Hwang, K.-K., \& Chang, J. (2009). Self-cultivation: Culturally sensitive psychotherapies in Confucian societies. The Counseling Psychologist, 37(7), 1010-1032.

Ip, D., Lui, C. W., \& Chui, W. H. (2007). Veiled entrapment: A study of social isolation of older Chinese migrants in Brisbane Queensland. Ageing and Society, 27(5), 719-738.

Kim, K. H. (2007). Exploring the interactions between Asian culture (Confucianism) and creativity. The Journal of Creative Behavior, 41(1), 28-53.

Kim, J. Y., \& Sung, K.-T. (2000). Conjugal violence in Korean American families: A residue of the cultural tradition. Journal of Family Violence, 15(4), 331-345.

King, R., Cela, E., Fokkema, T., \& Vullnetari, J. (2014). The migration and well-being of the zero generation: Transgenerational care, grandparenting and loneliness amongst Albanian older people. Population, Place and Space, 20(8), 728-738.

Klok, J., Van Tilburg, T. G., Suanet, B., Fokkema, T., \& Huisman, M. (2017). National and transnational belonging among Turkish and Moroccan older migrants in the Netherlands: Protective against loneliness? European Journal of Ageing, 14(4), 341-351.

Laidlaw, K., Wang, D.-H., Coelho, C., \& Power, M. (2010). Attitudes to ageing and expectations for filial piety across Chinese and British cultures: A pilot exploratory evaluation. Aging \& Mental Health, 14(3), 283-292. 
Li, M. (2005). Chinese in Europe. In M. Ember, C. R. Ember, \& I. Skoggard (Eds.), Encyclopedia of Diasporas (pp. 656-663). Springer.

Lu, L., Cooper, C. L., Kao, S.-F., \& Zhou, Y. (2003). Work stress, control beliefs and well-being in Greater China: An exploration of sub-cultural differences between the PRC and Taiwan. Journal of Managerial Psychology, 18(6), 479-510.

Luo, M., \& Chui, E. W. (2016). An alternative discourse of productive aging: A self-restrained approach in older Chinese people in Hong Kong. Journal of Aging Studies, 38, 27-36.

Ma, G. (2015). Food, eating behavior, and culture in Chinese society. Journal of Ethnic Foods, 2(4), 195-199.

Millay, K., \& Streeter, C. M. (2004). Implicit harmony: An overview of Confucianism and Taoism and their gift to the Christian faith. Chinese American Forum, 19(3), 2-6.

Morgan, J. N. (1986). Unpaid productive activity over the life course. In Committee on Aging Society, Productive Roles in an Older Society (pp.73-109). National Academy Press.

$\mathrm{Ng}, \mathrm{S}$. H. (2002). Will families support their elders? Answers from across cultures. In T. D. Nelson (Ed.), Stereotyping and Prejudice Against Older Persons (pp. 295-310). MIT Press.

Pan, H., De Donder, L., Dury, S., Wang, R., De Witte, N., \& Verté, D. (2019). Social participation among older adults in Belgium's Flanders region: Exploring the roles of both new and old media usage. Information, Communication \& Society, 22(13), 1956-1972.

Pang, C. L. (1993). Tussen inpassing en identiteit: De Chinese gemeenschap in België (Between Insertion and Identity: The Chinese Community in Belgium). Hoger Instituut voor de Arbeid, KU Leuven, Leuven.

Probst, T. M., \& Lawler, J. (2006). Cultural values as moderators of employee reactions to job insecurity: The role of individualism and collectivism. Applied Psychology: An International Review, 55(2), 234-254.

Roh, H. W., Hong, C. H., Lee, Y., Oh, B. H., Lee, K. S., Chang, K. I... \& Son, S. J. (2015). Participation in physical, social, and religious activity and risk of depression in the elderly: A community-based three-year longitudinal study in Korea. PLOS ONE, 10(7), e0132838.

Rowe, J. W., \& Kahn, R. L. (1987). Human aging: Usual and successful. Science, 237(4811), 143-149.

Ryan, F., Coughlan, M., \& Cronin, P. (2009). Interviewing in qualitative research: The one-to-one interview. International Journal of Therapy and Rehabilitation, 16(6), 309-314.

Skeldon, R. (1994). Reluctant Exiles? Hong Kong University Press, Hong Kong.

Smits, F., Ruiter, S., \& Van Tubergen, F. (2010). Religious practices among Islamic immigrants: Moroccan and Turkish men in Belgium. Journal for the Scientific Study of Religion, 49(2), 247-263.

VERBI Software. (2017). MAXQDA 12 reference manual. Berlin, Germany: VERBI Software. Retrieved from https://www.maxqda.com/download/manuals/MAX12_manual_eng.pdf

Statistics Netherlands (2020). Population; sex, age, migration background and generation, 1 January. Retrieved November 5, 2020, from https://opendata.cbs.nl/statline/\#/CBS/en/dataset/37325eng/ table?ts $=1525890294932$

Tabet, E. R. (2016). Activity participation and older adults' well-being. SPACE: Student Perspectives About Civic Engagement, 2(1), 22-28.

Tang, Z. (1995). Confucianism, Chinese culture, and reproductive behaviour. Population and Environment, 16(6), 565-565.

Torres, S. (2002). Relational values and ideas regarding successful aging. Journal of Comparative Family Studies, 33(3), 417-431.

Torres, S. (2003). A preliminary empirical test of a culturally-relevant theoretical framework for the study of successful aging. Journal of Cross-Cultural Gerontology, 18(1), 79-100.

Turper, S. (2017). Fearing what? Vignette experiments on anti-immigrant sentiments. Journal of Ethnic and Migration Studies, 43(11), 1792-1812.

Varenne, H. (1977). Americans Together: Structured Diversity in a Midwestern Town. Teachers College Press.

Winstead, V., Yost, E. A., Cotten, S. R., Berkowsky, R. W., \& Anderson, W. A. (2014). The impact of activity interventions on the well-being of older adults in continuing care communities. The Journal of Applied Gerontology, 33(7), 888-911.

World Health Organization. (2015). World Report on Ageing and Health. World Health Organization.

World Health Organization. (2002). Active Ageing: A Policy Framework. Madrid, Spain: World Health Orgnization.

Yang, K.-S. (1981). Social orientation and individual modernity among Chinese students in Taiwan. Journal of Social Psychology, 113(2), 159-170. 
Yeh, K.-H., \& Bedford, O. (2003). A test of the dual filial piety model. Asian Journal of Social Psychology, 6(3), 215-228.

Yu, J., \& Bairner, A. (2011). The Confucian legacy and its implications for physical education in Taiwan. European Physical Education Review, 17(2), 219-230.

Yum, J. O. (1988). The impact of Confucianism on interpersonal relationships and communication patterns in East Asia. Communication Monographs, 55(4), 374-388.

Yun, S. H. (2013). An analysis of Confucianism's Yin-yang harmony with nature and the traditional oppression of women: Implications for social work practice. Journal of Social Work, 13(6), 582-598.

Yunong, H., \& Wu, L. (2012). Correlates of life satisfaction among older people in China: An examination of two cultural variables. Aging \& Mental Health, 16(8), 1028-1038.

Publisher's note Springer Nature remains neutral with regard to jurisdictional claims in published maps and institutional affiliations.

\section{Authors and Affiliations}

\section{Honghui Pan ${ }^{1}$ (D) Tineke Fokkema ${ }^{2,3}$ (D) Renfeng Wang ${ }^{1,4} \cdot$ Sarah Dury $^{1,5}$ (D) Liesbeth De Donder ${ }^{1}$ (i)}

1 Faculty of Psychology and Educational Sciences, Vrije Universiteit Brussel (VUB), Pleinlaan 2, 1050 Brussels, Belgium

2 Netherlands Interdisciplinary Demographic Institute (NIDI)- KNAW/University of Groningen, Lange Houtstraat 19, 2511 CV The Hague, The Netherlands

3 Department of Public Administration and Sociology, Erasmus School of Social and Behavioural Sciences, Erasmus University Rotterdam, Rotterdam, The Netherlands

4 Xi'an International Studies University, Xi'an 710128, China

5 Research Foundation Flanders (FWO), Egmontstraat 5, 1000 Brussels, Belgium 